\title{
Treatment of periodontal defect caused by iatrogenic damage: Case report
}

\section{Leczenie ubytku tkanek przyzębia wywołanego przez uszkodzenie jatrogenne - opis przypadku}

\author{
Raif Alan ${ }^{1, A-E}$, Arslan Terlemez ${ }^{2, C, E}$ \\ ${ }^{1}$ Department of Periodontology, University of Necmettin Erbakan, Konya, Turkey \\ 2 Department of Endodontics, University of Necmettin Erbakan, Konya, Turkey \\ A - research concept and design; $\mathrm{B}$ - collection and/or assembly of data; $\mathrm{C}$ - data analysis and interpretation; \\ $D$ - writing the article; $E$ - critical revision of the article; $F$ - final approval of article
}

Address for correspondence

Raif Alan

E-mail: drraifalan17@gmail.com

Funding sources

none declared

Conflict of interest

none declared

Received on February 21, 2017

Revised on April 04, 2017

Accepted on June 13, 2017

\begin{abstract}
Endo-perio lesion is the association of periodontal and pulpal disease contained in the same dental site. In this case, periodontal plastic surgery was performed for the treatment of a periodontal defect that occurred as a result of iatrogenic perforation during endodontic treatment.

A 45-year-old female patient was referred because of a non-aesthetic condition and gingival pain in the maxillary anterior area. It was diagnosed as an endo-perio lesion of primary endodontic with secondary periodontal involvement. Initial treatment including the removal of etiological factors, scaling and root planning, and oral hygiene instruction was carried out. After phase I therapy, for treatment of the remaining gingival recession, a laterally positioned flap (LPF) design, which has an excellent post-operative healing process, was combined with platelet-rich fibrin (PRF) obtained from autologous blood. The usage of a LPF design combined with PRF for the treatment of the endo-perio lesion as a result of iatrogenic damage showed satisfactory results such as root coverage, an aesthetic condition with an adequate band of keratinized tissue, and reduced postoperative discomfort.
\end{abstract}

Key words: gingival recession, periodontal surgery, blood platelets, fibrin

Słowa kluczowe: recesja dziąsła, chirurgia periodontologiczna, płytki krwi, fibryna

DOI

$10.17219 / \mathrm{dmp} / 74767$

Copyright

○ 2017 by Wroclaw Medical University

and Polish Dental Society

This is an article distributed under the terms of the

Creative Commons Attribution Non-Commercial License

(http://creativecommons.org/licenses/by-nc-nd/4.0/) 
Endo-perio lesion is a condition characterized by the association of periodontal and pulpal disease in the same dental element. As well as etiological factors such as bacteria, fungus, and viruses, several auxiliary factors such as trauma, root resorption, perforations and dental malformations have an important role in the development and progress of endo-perio lesion. ${ }^{1}$ Root perforations are significant complications of endodontic treatment. ${ }^{2}$ Also, when carelessly used, there are some endodontic materials that may damage periodontal soft and hard tissues, e.g. sodium hypochlorite. In addition, it has been reported that it hard and soft tissues? may be treated when hard and soft tissues are iatrogenically damaged by use of intra-canal medicaments. ${ }^{3}$

The objective of periodontal plastic surgery is to achieve predictable and aesthetic root coverage. Persistence of the soft tissue is a primary line of defense for saving the tissue from bacterial infection. ${ }^{4}$ Thus, in this report, laterally positioned flap (LPF) in combination with platelet-rich fibrin (PRF) was used in the treatment of gingival recession (GR) and alveolar bone necrosis occurring as a result of iatrogenic damage.

\section{Case Report}

\section{Examination}

A 45-year-old female patient was referred to the Department of Periodontology, Faculty of Dentistry, University of Necmettin Erbakan, because of a non-aesthetic condition and gingival pain in the maxillary anterior area. After medical history was obtained from the patient, it was found that she was systemically healthy and had received root canal treatment of the right central upper incisor about three days prior in another clinic. Discoloration of the tooth and soft and hard tissue necrosis on the buccal site was observed following intraoral examination (Fig. 1). Additionally, a broken piece of root canal file was observed in radiographic evaluation of the relevant tooth (Fig. 2A).

\section{Diagnosis}

Following consultation with specialist endodontist, endo-perio lesion in which a primary endodontic factor plays a role was diagnosed. It was seen that the tooth was

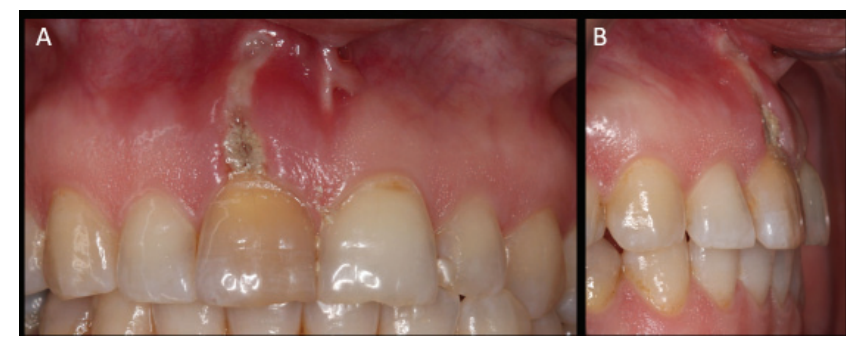

Fig. 1. A) clinical view of lesion, B) lateral view of lesion

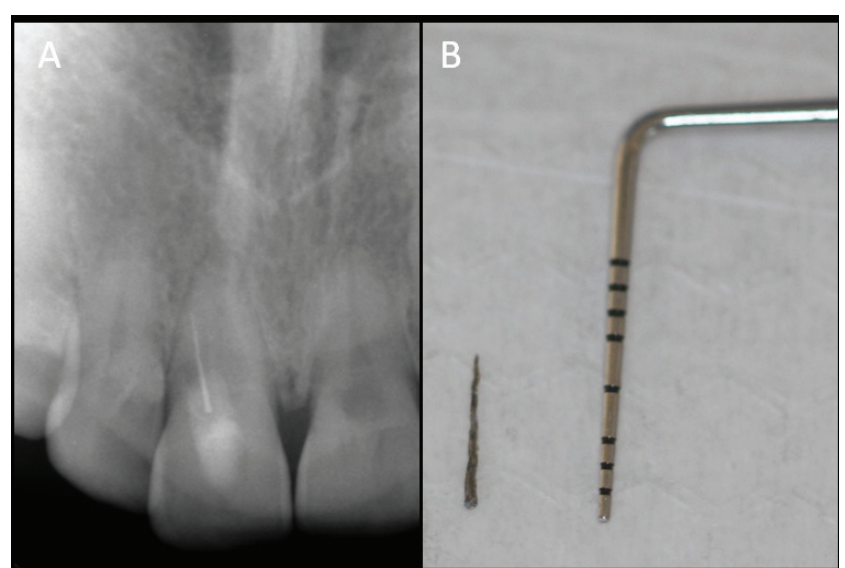

Fig. 2. A) periapical radiograph of maxillary right incisor tooth; B) broken endodontic root canal file

devitalized and asymptomatic in a percussion test, no pathological condition was observed around the tooth apical and the lamina dura was regular. It was concluded that, most probably, in the previous clinic, the root canal wasn't found during tooth canal treatment, a root canal device perforated the buccal part of the tooth, endodontic irrigants flooded tissues through the perforation and, as a result, this lead to tissue necrosis. Initial clinical measurements (probing depth, recession depth and keratinized tissue width) were recorded and, primarily, phase I periodontal treatment planned.

\section{Pre-surgical procedure}

The initial treatment was applied to remove the broken endodontic canal file (Fig. 2B) by entering the site where the buccal defect had occurred and necrotic tissue pieces were removed from the site. The temporary cement used in the previous clinic was removed and the internal sides of the cavity were washed with chlorhexidine and saline solution and then dried and re-covered with temporary cement. Subsequently, scaling and root planning was performed. The patient was given oral hygiene training and an appointment ten days later to monitor the clinical condition. Afterwards, surgical planning was scheduled to treat the remaining GR and restore the defect in the root (Fig. 3).

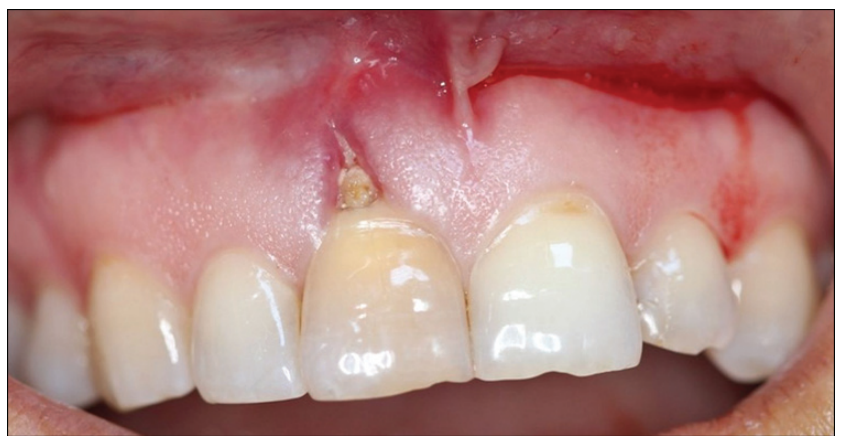

Fig. 3. Clinical view after phase I periodontal treatment 


\section{Surgical procedure}

Local anesthesia was administered following extra oral and intraoral antiseptic. A horizontal incision from the distal of the maxillary right lateral incisor tooth to the GR site was applied for LPF design. Afterwards, the incision was bound to vertical incisions performed on the distal of the lateral incisor tooth and the mesial of the GR site and a full-thickness flap was elevated. The soft tissue on the mesial of the GR site was de-epithelized. The marginal gingiva of the lateral incisor tooth was left in the original location (Fig. 4A). Following full-thickness flap elevation (Fig. 4B), bleeding was controlled and the endodontist specialist restored the root perforation with ProRoot ${ }^{\circledR}$ MTA (Dentsply, Maillefer, Switzerland) and the coronal part of the cavity with composite resin (3M ESPE, Dentsply Maillefer, Switzerland).

To prepare PRF, the blood of the patient was put into $9 \mathrm{~mL}$ glass-coated plastic tubes without anti-clotting agent (Becton Dickinson Vacutainer, Franklin Lakes, NJ, USA) and centrifuged immediately. The blood was centrifuged using a table centrifuge (PC 02, Process Ltd., Nice, France) for $12 \mathrm{~min}$ at $2700 \mathrm{rpm}$. PRF membrane was obtained by compressing using a PRF box (Process Ltd., Nice, France) (Fig. 5) and adapted into the defect area (Fig. 4C). The flap was stabilized with 4-0 Daylon ${ }^{\circledR}$ (Doğsan, Turkey) nonabsorbable sutures to cover the defect area (Fig. 4D).

\section{Post-surgical procedure}

The patient was given information about post-operative care and analgesic (flurbiprofen $100 \mathrm{mg}$, twice a day, if needed) and antiseptic oral rinse ( $0.12 \%$ chlorhexidine gluconate, twice a day) was prescribed. The patient was observed in the $1^{\text {st }}$ and $2^{\text {nd }}$ weeks following the operation to monitor post-operative healing. In the follow-up appointments, no complication was observed and good healing was recorded. The sutures were removed 2 weeks after surgery. After periodontal treatment was completed, Opalescence Endo whitening agent (Ultradent products, Inc., USA) was put into the coronal cavity and held for

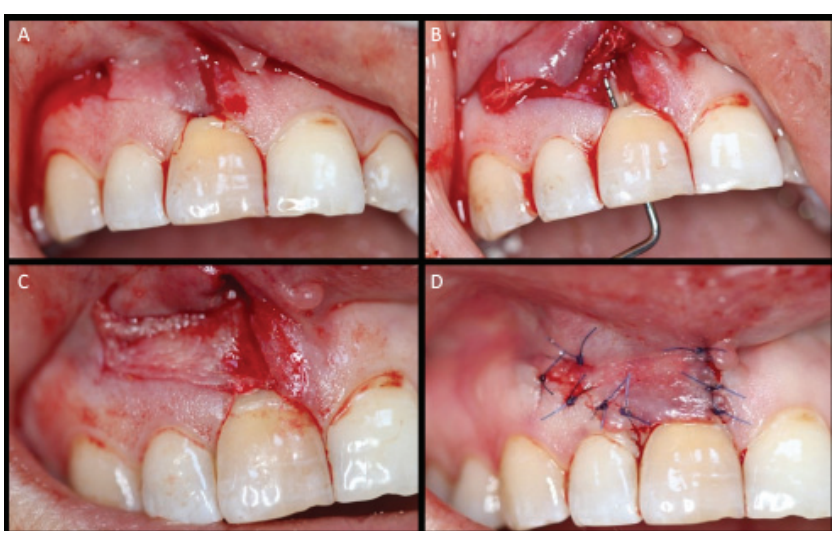

Fig. 4. A) preparing of flap; B) view of defect site; C) adaptation of PRF as a membrane; D) suture placement

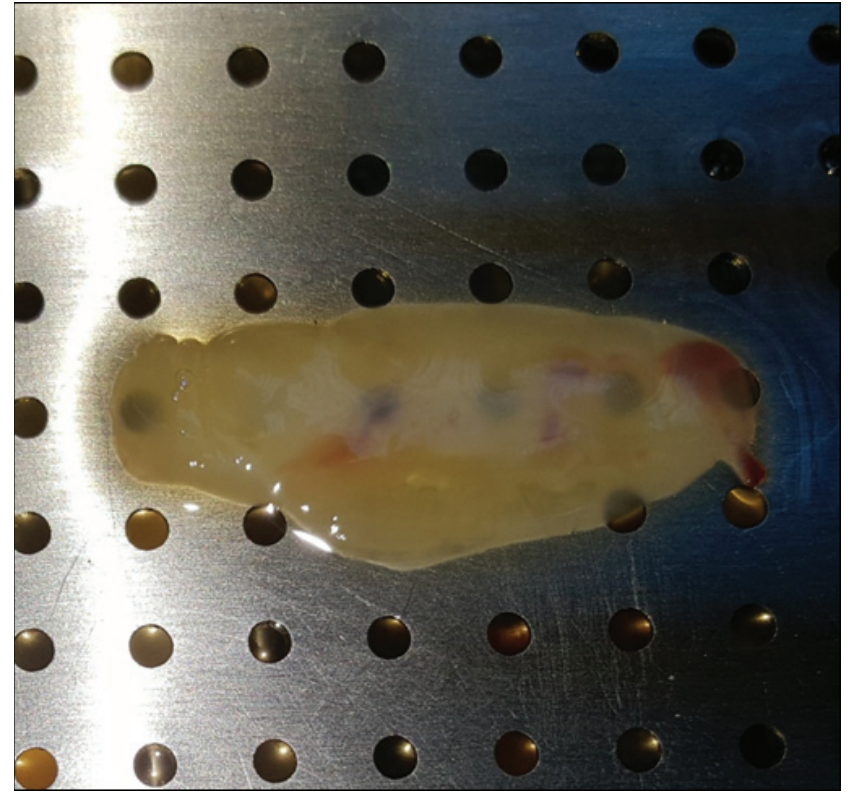

Fig. 5. PRF membrane

a week to remove the pre-existing coloration of the tooth. In order to manage sufficient whitening, a second whitening session was applied and the whitening agent was repeated. At the end of two weeks, sufficient whitening was achieved and the coronal cavity was restored with composite resins. An aesthetically satisfying result with a clinical asymptomatic situation and root coverage and sufficient band formation of keratinized tissue was observed 18 months after surgery (Fig. 6A-C). In addition, no symptoms in a percussion test applied to the tooth or any pathologic conditions in periapical radiography were observed (Fig. 6D). The initial and follow-up clinical measurements are presented in Table 1.

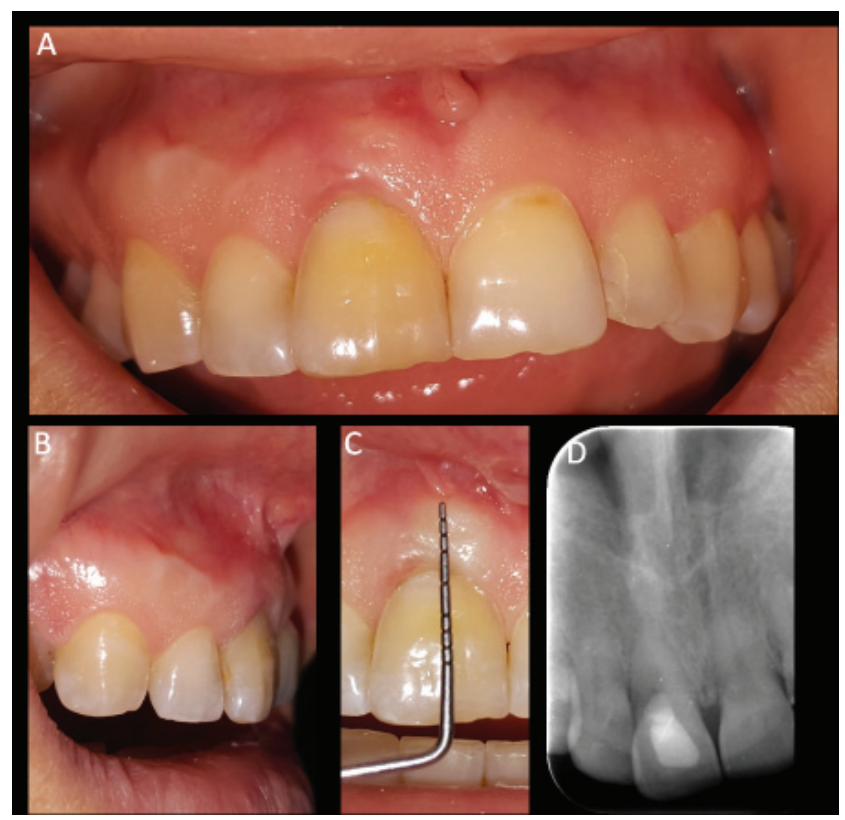

Fig. 6. A) clinical view of treatment site after 18 months; B) lateral view of treatment site after 18 months; C) post-operatif periapical radiograph of right central upper incisor 
Table 1. Initial and follow-up clinical measurements

\begin{tabular}{|c|c|c|}
\multirow{2}{*}{ Clinical parametrs } & \multicolumn{2}{|c|}{ Clinical measurements } \\
\cline { 2 - 3 } & initial $(\mathrm{mm})$ & follow-up $(\mathrm{mm})$ \\
PD & 3 & 2 \\
RD & 4 & 0 \\
KTW & 0 & 4 \\
\hline
\end{tabular}

PD - probing depth; RD - recession depth; KTW - keratinized tissue width.

\section{Discussion}

Endo-perio lesions occur when periodontal destruction merges in apical and becomes a periapical lesion or an endodontic lesion merges and becomes a periodontal lesion. ${ }^{1}$ Various methods such as free gingival graft, LPF, coronally positioned flap and membrane, sub-epithelial connective tissue graft (SCTG), acellular dermal matrix and guided tissue regeneration (GTR) with PRF are used in GR defects. ${ }^{5-7}$ SCTG, with its further predictability, is accepted as the gold standard. ${ }^{8}$ On the other hand, a second surgical site is required in SCTG, which may have a negative effect on patient comfort. ${ }^{9}$

PRF, providing several advantages including supporting wound healing, bone growth, maturation, graft stabilization, wound closure and homeostasis, is utilized to provide high concentrated growth factors to the bone defect areas..$^{10}$ Aleksic et al. ${ }^{11,12}$ concluded that the use of PRF and SCTG are equally effective in GR treatment. Furthermore, the authors stated that the use of PRF resulted in reduced post-operative discomfort and improved tissue healing.

Following diagnosis, the health and function of the tooth that has lost attachment after endo-perio lesion can be restored by using GTR in combination with removing the etiologic factors and grafting. ${ }^{13}$ In this report, due to the fact that there was insufficient keratinized tissue, LPF design, which has no additional surgical area and provides an excellent post-operative healing process, ${ }^{14}$ and PRF were planned for GR treatment.

In conclusion, a prognosis of endo-perio lesion as a result of iatrogenic damage can be healed and the usage of LPF in combination with PRF produced positive results such as root coverage and an aesthetically satisfying result with sufficient band formation of keratinized tissue and a tolerable level of post-operative discomfort for the patient.

\section{References}

1. Singh P. Endo-perio dilemma: a brief review. Dent Res J. 2011;8:39-47.

2. Menezes R, da Silva Neto UX, Carneiro E, Letra A, Bramante CM, Bernadinelli N. MTA repair of a supracrestal perforation: A case report. J Endod. 2005;31:212-214.

3. Reddy KKM, Shankar BS, Reddy KA, Reddy SN, Subhakar J, Reddy PSK. Localized interdental bone necrosis: A case report. J Int Oral Health, 2014;6:73-75.

4. Agarwal K, Chandra C, Agarwal K, Kumar N. Lateral sliding bridge flap technique along with platelet rich fibrin and guided tissue regeneration for root coverage. I Indian Soc Periodontol. 2013;17:801-805.
5. Chambrone L, Faggion CM Jr, Pannuti CM, Chambrone LA. Evidence-based periodontal plastic surgery: An assessment of quality of systematic reviews in the treatment of recession-type defects. J Clin Periodontol. 2010;37:1110-1118.

6. Hofmanner $\mathrm{P}$, Alessandri R, Laugisch $\mathrm{O}$, et al. Predictability of surgical techniques used for coverage of multiple adjacent gingival recessions - a systematic review. Quintessence Int. 2012;43:545-554.

7. Cortellini P, Pini Prato G. Coronally advanced flap and combination therapy for root coverage. Clinical strategies based on scientific evidence and clinical experience. Periodontol 2000. 2012;59:158-184.

8. Paolantonio M, Dolci M, Esposito $\mathrm{P}$, et al. Subpedicle acellular dermal matrix graft and autogenous connective tissue graft in the treatment of gingival recessions: a comparative 1-year clinical study. J Periodontol. 2002;73:1299-1307.

9. Zucchelli G, Mele M, Stefanini M, et al. Patient morbidity and root coverage outcome after subepithelial connective tissue and deepithelialized grafts: A comparative randomized-controlled clinical trial. J Clin Periodontol. 2010;37:728-738.

10. Corso MD, Toffler M, Ehrenfest DM. Use of an autologous leukocyte and platelet-rich fibrin (L-PRF) membrane in post-avulsion sites: An overview of Choukroun's PRF. J Implant Adv Clin Dent. 2010;9:27-35.

11. Aleksić Z, Janković S, Dimitrijević B, Pucar A, Lazić V, Leković V. Clinical impact of platelet rich plasma in treatment of gingival recessions. Srp Arh Celok Lek. 2008;136:95-103.

12. Aleksić Z, Janković S, Dimitrijević B, Divnić-Resnik T, Milinković I, Leković $V$. The use of platelet-rich fibrin membrane in gingival recession treatment. Srp Arh Celok Lek. 2010;138:11-18.

13. Aksel $\mathrm{H}$, Serper A. A case series associated with different kinds of endo-perio lesions. J Clin Exp Dent. 2014;6:91-95.

14. Zucchelli G, Mounssif I. Periodontal plastic surgery. Periodontol 2000. 2015;68:333-368. 